\title{
Interpreting Shell's 'Clear Thinking in Troubled Times'
}

\author{
RaLPh H. Johnson \\ Department of Philosophy \\ University of Windsor \\ Windsor, ON N9B 3P4, Canada \\ johnsoa@uwindsor.ca
}

\section{Introduction}

The Shell advertisement raises interesting questions at both the theoretical and the pedagogical level. The text bears very little resemblance to a typical advertisement; graphics are sparse, no product is being trumpeted, there is plenty of text, and it looks very much like an argument: it seems designed to persuade and give reasons and even deals with objections. What more could one ask? Nevertheless, I am going to argue that it is not a good idea to interpret this text as an argument (that is a theoretical issue), and certainly not a good idea to teach our students to appraise it as an argument (that is a pedagogical issue).

In what follows, I begin, then, by adopting the view-shared by the other contributors to the Teaching Supplement (van Eemeren and Houtlosser, Van Rees, and Jacobs)-that the text can reasonably be interpreted as an argument. Taken this way, it turns out that it is not a very good argument. The principle of charity suggests that if there were another plausible interpretation according to which the text fared better, we should take that interpretation. I then pursue such an interpretation, and that leads to a contrast between argument and advertising taken as species of persuasion. Using that contrast, I then re-examine the Shell text and find good reasons for rejecting the earlier interpretation. But my alternative interpretation then raises the question of how the text might better be analyzed, and that leads to a brief discussion of how one might analyze this text considered as advertising rather than as argument.

\section{The text taken as argument}

The Shell text meets the requirements for an argument in the traditional sense. We find in it reasons $(6-11)$ produced in support of a thesis-even though the thesis is never stated explicitly. Even from the perspective of the fortified concep- 
tion of argument that I presented in Manifest Rationality (2000), the text appears to be an argument. For it contains both an illative core (e.g., 6-11) and a dialectical tier (e.g., 4-5, 12-13 etc.). It certainly seems designed to persuade; and it appears as well to satisfy the requirement of manifest rationality: it at least has the appearance, if not the substance, of rationality.

Thus interpreted, the text can then be analyzed using the process that one might use on any argument. My approach would be similar in many respects to that given by Tindale (with some few exceptions not worth going into here) which he analyzes using what he calls a rhetorical approach $(1999,125-144)$. In this section of the paper, I will be piggybacking on his analysis.

I shall not spend much time discussing the problems with the illative core, which Tindale has well discussed. He points out the number of claims that are presented without evidence $(129,142)$; there is irrelevance $(131,132)$; there is bad causal reasoning (143-44). Equally interesting to me are the number of criticisms Tindale makes that have to do with either the indirect, or implicit nature of the reasoning, or the absence of reasons altogether. ${ }^{1}$ Look at the ways he categorizes what takes place: "indirect assertion" (129); "in some implied way" (129); "implicit claim" (130); "correlation and causal claim is suggested" (130); "implies as much," 130; "hidden claim" (131); "forgotten here" (135); "what is omitted" (143). He also refers to "false information" and "what is omitted." I take these to be highly suggestive of what is going on here and shall be returning to this point shortly. What we have noticed thus far is that the reasoning is both problematic and indirect/elliptical.

Let me turn next to the question of dialectical adequacy (which 1 understand somewhat differently than Tindale does). By dialectical adequacy, I mean that the arguer has responded appropriately to the objections and criticisms that have been pressed, or might have been pressed, against the argument. Does the Shell argument achieve dialectical adequacy? I think there are good reasons to conclude that it does not. ${ }^{2}$

First, look at line 4 (Tindale, 129): Here Shell says, "slogans, protests and boycotts don't offer answers." Here Shell alludes to but fails to engage with the alternative positions. It does not say why those who opted for the boycott did so, or what was wrong with or inadequate about their position. Second, look at line I4 (Tindale, 131): the text refers to charges of environmental devastation but gives no specifics. Who made those charges, and with what evidence or reasoning? Shell would have known in detail precisely what these charges were and would likely have had some response. Some readers would certainly have been interested in how Shell will respond to such charges. ${ }^{3}$ Third, look at line 23 (Tindale, 133): here the authors identify a friendly suggestion that Shell pull out of Nigeria. They reject it but they never indicate the background and the reasoning behind the proposal. Fourth, look at lines 35-36 (Tindale, 135). The authors refer to "some campaigning groups...." But again they do not bother to tell us who these groups are or 
what reasons they gave for their views. Here again we find an indirectness similar to that in the illative core.

I am struck by this failure to achieve dialectical adequacy. For Shell had to have known in detail what the objections and criticisms alluded to were, and the reasons behind them. Any multinational corporation these days must be sensitive to its standing in the public and with its shareholders that will have heard these criticisms and will want the company's response. If from nothing else than a strategic point of view, Shell would have had an interest in learning of and rebutting such charges. It is just not plausible to think that Shell did not know these objections. Nor is it plausible to think that Shell would not have been able to develop sophisticated lines of defense and rebuttal. Anyone who has read an Annual Report put out by any modern corporation will find the section in which various proposals have been made by shareholders. Typically, these are quoted; reasons, sometimes a supporting statement are given for the proposal; and then the Board gives its recommendation and detailed reasoning to support it. So the failure to achieve dialectical adequacy in this text does not appear to be ascribable to oversight, or the result of a lack of skill. It has to have been intentional to some degree-another suggestive point.

Given that Shell had the expertise required to produce a good argument, why did they not do so? Perhaps a hermeneutic pause is called for. Perhaps we have been hasty in taking this advertisement as an argument; perhaps it should be viewed in another light.

\section{The advertisement taken as a communication}

Let's go back to the starting point. What's beyond dispute is that the text is clearly an advertisement, or as some say an "advertorial." Advertising is primarily a response to a marketing situation. The process begins with the definition by the company of the "problem" it wishes to solve. ${ }^{4}$ I am not altogether sure what the problems were in this case, though my guess is that Shell found itself criticised for its involvement in Nigeria. It had received some bad press, and Shell hoped this message would help reposition it as a trustworthy and responsible company by presenting itself as having acted responsibly and being a voice of reason. ${ }^{5}$

As consumers, we can only guess what their objectives were. The account executives for Shell knew those objectives, as did those at the advertising company responsible for the content and format of this ad. But the objectives are sometimes not discernible from the message that actually appears. ${ }^{6}$ Now, we have seen the text does not fare well as an argument, yet it is quite possible that the ad achieved the objectives its authors had in mind. It might have been an effective advertisement. Even if we could get the ear of those responsible and point out to them all of the problems we have mentioned, my suspicion is that they would not see those criticisms as germane. Suppose, for example, we went to Shell and argued as follows: "That is a poor ad because it contains bad causal reasoning and 
irrelevance" (as above). Does anyone suppose that the Shell account executives would be inclined to change the ad, even if they agreed? If they have evidence that the advertisement was achieving its objectives,' then whether or not it does so by fair logical means or foul would be of little, if any, concern to them.

Thus far we have seen that, taken as an argument, this text is not a good argument. We have also seen that, taken as a message, it is possible that it was effective in achieving certain objectives (whose precise nature we can only speculate about.)

Let's review some pertinent facts:

1. Shell knows how to produce a good argument. Basis: Shell has the necessary expertise. Shell has or can get all the necessary information. (I regard these claims as obvious.)

2. Shell had the time to produce a good argument. Basis: They did not need to run the ad until they were good and ready. (Ditto.)

3. Shell produced a text that has the appearance of an argument. (Argued above.)

4. Shell produced an argument that is substantively poor. (Argued above.)

5. Shell did not intend to produce a good argument. (Conclusion from 1-4)

6. Shell had an objective(s) it wanted to achieve in this message. Basis: No modern multinational corporation engages in such public communication without a clearly stated objective. (Obvious.)

7. Shell has a good working knowledge of how to achieve these objectives. (Obvious.)

8 . Shell believed this message achieved these objectives. Otherwise they would not have released the ad.

Now: What follows from 1-8? The conclusion I draw is that this text has been deliberately fashioned with the appearance of argument and that this appearance is crucial to the achievement of their objective. It very much looks like Shell is using the dialectical material it refers to as window dressing, that they have no real desire or intention to engage in argumentation with their opponents. Shell chose to design a message that has the appearance of argument but lacked the substance of argument. I conclude then that, despite appearances, it is not best construed as an argument. In the next section, I support this claim further by contrasting advertising and argument, considered as communication designed to persuade.

\section{Advertisement contrasted with argument}

In Logical Self-Defense (1994), we (Johnson and Blair) say that advertisements mimic argumentation (220). Perhaps more accurately, advertising is parasitic upon the practice of argumentation because it feeds off the practice of argumentation while not contributing to that practice; ads have the appearance but not the sub- 
stance of argumentation. The box below encapsulates what I take to be some of the fundamental differences between advertisements and arguments.

\begin{tabular}{|l|l|}
\hline ARGUMENT & ADVERTISING \\
\hline - seeks to persuade rationally & $\begin{array}{l}\text { - seeks to persuade psychologically } \\
\text { and/or emotionally } \\
\text { - colies heavily on implication } \\
\text { - constituted by assertions } \\
\text { - clearly formulated claims } \\
\text { - seeks total evidence }\end{array}$ \\
$\begin{array}{l}\text { - vague and ambiguous claims } \\
\text { seriously }\end{array}$ & regularly suppresses evidence \\
\end{tabular}

Notice how many of the characteristics in the right column have turned up in the Shell advertisement. We have seen that it relies heavily on implication, that evidence is suppressed and that counterargumentation is only apparently taken into consideration. It would not be difficult to show that it seeks to persuade using psychologically designed strategies and that it cloaks its claims purposely in vague and ambiguous language. (This would be a good exercise for students.)

If the above contrast is right, then it follows that pointing out fallacies and other logical errors in advertisements is misguided, for two reasons. First, the critique shows nothing because an advertisement wasn't designed to work as argument in the first place.

It would be rather like interpreting a poem as an argument, and finding it was a bad argument. ${ }^{8}$ To criticize an advertisement for suppressing evidence, if one thinks that this will be taken by the authors of the advertisement as revealing a flaw in their advertisement, is reminiscent of Kant's definition of wasted motion: "one man milking the he goat while the other holds a sieve underneath." Indeed the authors of this message had to have known what they were doing; ads don't come into being spontaneously or haphazardly but rather with great attention to the entire message. We may be sure that the authors of the Shell advertorial knew exactly what they were doing - relying heavily on implications - and did it anyway. Why? Here is David Ogilvy in Confessions of an Advertising Man: "Dorothy Sayers, who wrote advertisements before she wrote whodunits and Anglo-Catholic tracts, says: 'Plain lies are dangerous. The only weapons left are suggestio falsi and suppressio veri" (1964). Ads often fail to present evidence that is known to the advertiser but held back from the consumer and which would, were it known to the consumer, alter her opinion. Hence the alert consumer needs to develop an 
eye for what has not been said! We would do better by our students to call attention to this sort of strategy than to treat ads as arguments which are typically defective because fallacious.

Second, to critique an advertisement as an argument is likely to create the illusion that one has seen through the advertisement, shown it to be fallacious and thereby, as it were, disarmed it. The critic may believe, falsely if the evidence is correct, that he or she is thus immune to the lures of the advertisement.

A third reason to oppose to such interpretation is that it accords advertisements a false dignity they do not merit. The intellectual product we call an argument deserves to be taken very seriously because of the power it has to do intellectual work. There are other kinds of work (advertising, poetry, and paintings) and other kinds of intellectual work (explanation, theory construction, essay, etc); each have its own role and its own standards of achievement, and I see nothing gained by assimilating them to one another. ${ }^{9}$ This point is dealt with in my Manifest Rationality (2000, pp. 21-27).

\section{An alternative approach}

I have just been arguing that it is not a good idea to approach ads as arguments; I have also argued that it is not possible for us generally to approach them from an internal point of view; i.e., to appraise their effectiveness in terms of the market objectives (without gaining access to inside information). If we are interested in teaching students to confront advertising effectively, a different approach will be needed. In Logical Self-Defense, Blair and I developed and presented just such an approach, which we based on the ideas presented by someone who knows the business well, Carl Wrighter. His classic book-I Can Sell You Anything-is a manual of insights into advertising strategies. What we have done in our text is slightly reorganize his approach under five basic headings (two of which were mentioned in the Ogilvy quote above):

1. Semantic license. One strategy is the intentional use of ambiguity, vagueness and loaded terms. Example: The classic Coke slogan: "Coke is it!"

2. Suppressed evidence. A prominent strategy is the failure to include available evidence that is relevant to the conclusion and of which the authors are in possession.

3. False or misleading implication. Related to the above is that strategy whereby the advertiser makes a claim that is true but implies (in some sense) another claim that is false.

A classic example of the second and third strategies used together occurred in a Volvo ad that appeared in the late $60 \mathrm{~s}$. When Volvo first began to take the North American market seriously, they produced an ad designed to create the impression of a car that was endurable which claimed (truthfully): "9 out of 10 Volvos sold in the last 10 years are still on the road." Now what did this claim imply? That Volvo was a durable car, with $90 \%$ of them lasting for ten years. But wait that is not 
what was said. They didn't say, "90\% of our cars will last (stay on the road in decent condition)." If you assume (and this is always unwise) distribution in sales equitably divided by year over this ten year period, and then you can wind up with that conclusion of super endurance. But should you make that assumption? Of course not. Here is a piece of suppressed evidence [clearly suppressed not just missing]: The bulk of Volvo sales had occurred within the previous five years. 7 out of 10 Volvos sold in the US in the previous 10 years had actually been sold within the previous 5 years. When they unearthed this piece of information, two logic students approached a Volvo vice-president and pointed out the misleading nature of the implication. He responded: "Look, it's true, so it cannot be misleading." Notice he did not say: "We will reword the claim so as to avoid this unintended misimplication." He produced this specious reasoning (which he had to know was specious, since much of advertising relies on making claims that are literally true but have false implications).

4. The appeal to the psyche. Wrighter points out how much advertising is designed to work at a psychological level, attacking weak spots in the ego of the consumer: fear and pride and one's sense of identity being the chief weapons.

5. The use of graphics and music. Particularly on TV, advertisers have developed the ability to use of images and sound.

If one looks back at the Shell ad, one can see that the first four strategies are much in evidence.

I suggest, then, that the best way to use advertising in the classroom is not as presenting us with arguments that need to be analyzed and evaluated, but rather as designing messages meant to persuade psychologically. Advertorials, like the Shell one we have been discussing, should be contrasted with argument rather than lumped together with it. Analysis of them requires a different approach.

\section{Conclusion}

I began by stating that this is an interesting and challenging text that raises both theoretical and pedagogical issues. The theoretical issue that it raises is what is an argument and whether it is useful to interpret ads this way. The pedagogical issue is how best to teach our students about confronting advertisements. It seems to me that although this text bears a certain resemblance to argument from a structural point of view (i.e, it appears to be engaged in giving reasons for claims), its obvious violation of the requirements of argumentation make it, at best, a marginal example; hence, it is not particularly illuminating to critique it as an argument. I then discussed other ways of analyzing the text, which then led to a comparison of advertising, and argument that again revealed that this text lacks the features associated with argument. Finally, I suggested that evaluating as an argument was ill advised and recommended an alternative approach. 


\section{Notes}

Already an alert reader might begin to have doubts about the propriety of interpreting such a text as an argument.

Tindale seems to agree with me on this point, for he notes that "dialectically this overlooks some serious counter-argumentation"(134) and that Shell is "avoiding key objections" (142).

${ }^{3}$ Greenpeace. The Body Shop and Friends of the Earth all took out ads in important international newspapers in which they charged that the activities of Shell and other multinational corporations "have led to widespread degradation and pollution of the regions; lakes, rivers land and air." They would surely have been interested in Shell's response.

"Advertising, as most of those in the business will say, is a response to a marketing problem. See David Hayes, "Die Hard," Business, September, 2001, p. 6: "The first step in the making of an ad is to prepare a brief-a one or two page manifesto outlining the strategic goals the client wants the advertising to address for a product or service."

"Herein my analysis agrees with those of van Eemeren and Houtlosser, and van Rees.

"The classic example here is the Avis campaign of the 60 s featuring the slogan

"We Try Harder" whose objective was not to overtake Hertz as \#1 but rather to install Avis as \#2 (Glatzer 1970).

${ }^{7}$ Typically the advertising firm would have done follow-up testing to discover whether the ad was effective.

"Years ago, Jonathan Adler (1985) undertook such an approach to Herrick's poem

"To the Virgins, to Make Much of Time." He stated: "I suppose that if we flesh out the assumptions the standardized argument will be valid but of questionable soundness" (61).

${ }^{9}$ I develop this point at somewhat greater length in Johnson (2002).

\section{References}

Adler, J. (1985). "What are the Limits to Reconstruction?" Informal Logic (7:1), 61-63.

Van Eemeren, F. H. and P. Houtlosser. (2002), "Clear Thinking in Troubled Times": An Integrated Pragma-Dialectical Analysis. Informal Logic (Teaching Supplement), $21: 2$ (Spring 2001), TS17-30.

Glatzer, R. (1970). The New Advertising: The Great Ad Campaigns from Avis to Volkswagen. New York: The Citadel Press.

Jacobs, S. (2002). "The Pragmatic and Dialectical Dynamics of an Illegitimate Argument", Informal Logic (21:3), TS31-38, (in this issue).

Johnson, R. H. (2000.) Manifest Rationality: A Pragmatic Study of Argument. Mahwah, NJ: Lawrence Erlbaum Associates.

Johnson, R. H. (2002). Manifest Rationality Reconsidered: A Response to My Fellow Symposiasts. Argumentation, forthcoming.

Johnson, R.H. and J.A. Blair. (1994.) Logical Self-Defense. New York:: McGraw-Hill.

Ogilvy, D. (1964). Confessions of an Advertising Man. New York: Dell.

Tindale. C. (1999). Acts of Arguing: A Rhetorical Model of Argument. Albany: State University of New York Press.

Van Rees, M.A. 2002. 'A Dialectical Analysis of 'Clear Thinking in Troubled Times'. Informal Logic (Teaching Supplement), 21:2 (Spring 2001), TS1-16. 
Ogilvy, D. (1964). Confessions of an Advertising Man. New York: Dell.

Tindale. C. (1999). Acts of Arguing: A Rhetorical Model of Argument. Albany: State University of New York Press.

Van Rees, M.A. 2002. 'A Dialectical Analysis of 'Clear Thinking in Troubled Times'. Informal Logic (Teaching Supplement), 21:2 (Spring 2001), TS1-16.

Wrighter, C. (1972). I Can Sell You Anything. New York: Ballantine Books. 